\title{
In-situ Observation of Irradiation Induced Defects in Fe and Fe-Cr Alloys
}

\section{Zhongwen Yao}

Queen's University, Kingston, Ontario, Canada

The selection of structure materials is a key issue for achieving the success of future fusion and advanced fission reactors. Candidate materials for these applications include reduced-activation ferritic-martensitic (RAFM) steels with Cr contents ranging between 9-12\%. These steels have better thermal properties and higher swelling resistance than austenitic steels, but may become embrittled under irradiation at temperatures less than about $400^{\circ} \mathrm{C}$ [1-3]. It is important to develop a detailed mechanistic understanding of the development of radiation damage in ferritic alloys, which is lacking at present. The work reported here is part of this endeavor. The experiments of heavy-ion irradiation in iron was performed by using Argonne IVEM-Tandem Facility, which comprises an electron microscope linked to a heavy-ion accelerator. Thin foils of pure Fe were irradiated with $150 \mathrm{keV} \mathrm{Fe}+$ ions at temperatures $30-500^{\circ} \mathrm{C}$. Dynamic observations under weak-beam diffraction conditions followed the evolution of damage over doses 0-10 dpa. At low doses, $\leq 1 \mathrm{dpa}$, damage took the form of small, isolated dislocation loops with Burgers vectors $b=\langle 100>$ and $1 / 2<111>$. Loops with $b=1 / 2<111>$ were highly mobile, moving by discrete hops from one position to another, both during and after ion irradiation. At temperatures $\leq 300^{\circ} \mathrm{C}$ and doses $\geq 1 \mathrm{dpa}$, complex microstructures developed in thicker regions of the foils. First strings of several loops, all with the same $1 / 2<111>$ Burgers vector formed, involving elastic interactions and cooperative movement of individual loops. Then larger loops were produced by the coalescence of loops in a string. In high-purity Fe irradiated at $300^{\circ} \mathrm{C}$, further coalescence and complex glide and climb processes led to the formation of large (several $\mu \mathrm{m}$ ) finger-shaped loops with $b=1 / 2<111>$ and large shear components. By this stage the loop nature could be shown to be interstitial. At temperatures higher than $300^{\circ} \mathrm{C}$, squareshaped sessile edge interstitial loops with $\mathrm{b}=\langle 100\rangle$ nucleated and grew to large sizes. At temperatures $\leq 450^{\circ} \mathrm{C}$, these $<100>$ loops co-existed with $1 / 2<111>$ loops, but at $500^{\circ} \mathrm{C}$ only $<100>$ loops formed. Small voids were found at $300^{\circ} \mathrm{C}$. In this contribution these dynamical processes will be shown in the form of videos.

References

1. D.S. Gelles, J.Nucl. Mater. 233-237 A (1996) 293.

2. R.L. Klueh and D.R. Harries, High Chromium Ferritic and Martensitic Steels for Nuclear Applications, American Society for Testing and Materials, West Conshohocken, PA, USA (2001).

3. K. Ehrlich, Fus. Eng. Des. 56-57 (2001) 71. 